\title{
Patient Safety Culture in a Teaching Hospital in
} Eastern Province of Saudi Arabia: Assessment and Opportunities for Improvement

\author{
Afnan Aljaffary $\mathbb{D}^{\prime}$ \\ Fatemah Al Yaqoub ${ }^{2}$ \\ Reem Al Madani ${ }^{3}$ \\ Hessa Aldossary (D' \\ Arwa Alumran (DD \\ 'Department of Health Information \\ Management \& Technology; College of \\ Public Health; Imam Abdulrahman Bin \\ Faisal University, Dammam, Saudi Arabia; \\ ${ }^{2}$ Risk Management and Patient Safety \\ Department; Dammam Medical \\ Complex, Dammam, Saudi Arabia; ${ }^{3}$ Risk \\ Management Unit, Directorate of Quality \\ and Safety, King Fahad Hospital of the \\ University, Imam Abdulrahman Bin Faisal \\ University, Dammam, Saudi Arabia
}

Correspondence: Afnan Aljaffary Imam Abdulrahman Bin Faisal University, King Faisal Road, Dammam, KSA, 342I2, Saudi Arabia

Tel +9660I33338086

Email aaljaffari@iau.edu.sa
Purpose: The objective of the present study is to explore the perceptions of patient safety culture (PSC) among King Fahd University Hospital's (KFUH) employees and to develop recommendations to overcome the factors that impede the integration of PSC in the study setting. Methods: This is a cross-sectional study that assessed the level of PSC at KFUH. This study used the Hospital Survey on Patient Safety Culture tool from all KFUH healthcare workers $(\mathrm{n}=900)$ in 2018.

Findings: The response rate of the study was $67 \%$. Findings show that KFUH excelled in three PSC composites: continuous organizational learning, feedback and communication about error, and frequency of events reported. In contrast, staffing, teamwork within units, and non-punitive response to error yielded low composite scores.

Originality/Value: The strength of the present study was the use of a valid questionnaire that has been used widely in the literature with a large sample size, which yielded valid results. It is, to our knowledge, the first research study that analyzes health workers' perceptions on patient safety culture in a teaching hospital in Eastern Province in KSA and compares it with Agency for Healthcare Research and Quality (AHRQ) and Saudi Hospital Survey on Patient Safety Culture (HSPSC). Results from the study highlight the need to employ an adequate number of workers, implement continuous patient safety training programs, and adopt safety programs and policies.

Keywords: patient safety culture, teamwork, non-punitive response to error, hospital survey

\section{Introduction}

A culture of patient safety has been widely acknowledged as a critical measure of quality health service. Major health organizations including the World Health Organization (WHO) and international accreditation institutions such as the Joint Commission International (JCI) have, in fact, emphasized the need to foster a culture of safety as an effective approach for sustainable safety improvement. ${ }^{1}$ The JCI defines patient safety culture (PSC) as the product of personal and group beliefs, opinions, proficiencies, and activities that measure a hospital's commitment to quality and safe healthcare. ${ }^{2}$ Previous studies suggest that PSC enhances the quality of care, prevents errors, improves patient outcomes, and reduces healthcare costs. $^{3}$ As the demand for quality healthcare increases, hospitals are faced with an increased need to establish a culture of patient safety.

Although PSC is associated with numerous benefits, a number of healthcare institutions have encountered diverse challenges during its integration. It has been 
speculated that the success of PSC requires clear communication, collaboration across departments, continuous organizational learning, supportive leadership, adequate personnel, acknowledgement of adverse events, and non-punitive attitudes towards incidents and error reporting. ${ }^{4-6}$ Studies on factors that limit the success of PSC programs have reported diverse findings. One study found that ineffective processes, unsupportive leadership, and lack of patient management skills impeded the integration of PSC in Iranian hospitals. ${ }^{7}$ A similar assessment found that a lack of feedback and clear communication affected PSC implementation in Saudi Arabian hospitals. ${ }^{8}$ A comprehensive understanding of the issues that limit the adoption of PSC will aid in developing interventions for better implementations for PSC in KSA hospitals.

The present study aims to explore the perceptions of PSC among diverse health care providers at King Fahd University Hospital (KFUH) and to determine the challenges of PSC practice at KFUH. Such knowledge about perceptions and challenges is valuable not only to administrators, managers, and policy makers of hospitals but also to individuals seeking healthcare services. Moreover, the study aims to understand factors (related to respondents) that may affect the patient safety aggregate score and consequently the most critical to enhance patient safety, improve health quality, reduce error rates, and decrease healthcare costs.

\section{Materials and Methods Study Design}

This is a cross-sectional study to assess the level of PSC.

\section{Setting}

The study was conducted at a secondary teaching hospital, Eastern Province of Saudi Arabia, with a capacity of 300 beds. The hospital is accredited by the CBAHI and JCI.

\section{Participants}

The survey included all employees from each of KFUH's departments including and not limited to medicine, surgery, obstetrics, pediatrics, intensive care unit, psychiatry, laboratory, radiology, and administrative departments.

\section{Variables}

The dependent variable was the total score in 12 different domains, including overall perceptions of patient safety; supervisor/manager expectations and actions promoting patient safety; organizational learning - continuous improvement; teamwork within units; teamwork across units; non-punitive response to error; staffing; management support for patient safety; handoffs and transitions; communication openness; feedback and communication about error; and frequency of events reported. The independent variables include job position, direct interaction with patients, number of working hours, and number of years working in the hospital.

\section{Data Sources/Measurement}

Patient safety culture was evaluated using the Hospital Survey on Patient Safety Culture (HSOPSC), a reliable and validated survey tool that includes questions to assess the 12 domains of PSC. The domains and their associated questions are presented in Table 1.

\section{Sample Size}

As part of the Saudi Central Board for Accreditation of Healthcare Institutions (CBAHI) and Joint commission accreditation (JCI) requirements, KFUH is obligated to conduct annual PSC surveys aimed at evaluating the hospital's compliance with safety culture standards. ${ }^{9}$ According to the accreditation standards, $>60 \%$ of the employees of a hospital should participate in the PSC surveys. While participation was optional, all employees were encouraged to participate in the present survey to fulfill the CBAHI and JCI requirements. The survey was sent by email to all KFUH employees $(\mathrm{n}=900)$.

Bias: Recall bias could have been introduced, as the data rely solely on the employees' recollection of their PSC practice in the selected healthcare facility.

\section{Statistical Methods}

Statistical Package for Social Science (SPSS) version 25 was used to conduct the statistical analyses. ${ }^{10}$ The summary statistics are presented as counts and percentages of categorical variables and as measures of central tendency for continuous variables.

The total PSC score was estimated by computing the scores in the 12 domains, after reverse scoring negative questions. Thus, higher scores indicate better PSC. Means and standard deviations were calculated for all variables in the scale.

With regards to analysis of survey composite scores, items were scored on a five-point frequency scale (including a neutral category). The HSOPSC included both positively and negatively worded items; negatively worded items were 
Table I Cronbach's $\alpha$ and Distribution of Positive Responses for Survey Composites

\begin{tabular}{|c|c|c|c|c|}
\hline & & $\begin{array}{l}\text { Average \% Positive } \\
\text { Response }\end{array}$ & Average & SD \\
\hline & Overall perceptions of patient safety (Cronbach's $\alpha=0.5 \mid 2$ ) & 56.9 & 885.5 & 931.3 \\
\hline I.I & It is just by chance that more serious mistakes do not happen around here (R) & 31.5 & 123 & 138.6 \\
\hline 1.15 & Patient safety is never sacrificed to get more work done & 68.4 & 268 & 250.3 \\
\hline 1.17 & We have patient safety problems in this unit $(\mathrm{R})$ & 54.5 & 207 & 206.4 \\
\hline \multirow[t]{2}{*}{1.18} & Our procedures and systems are good at preventing errors from happening & 73 & 785 & 335.8 \\
\hline & $\begin{array}{l}\text { Supervisor/manager expectations and actions promoting patient safety } \\
\text { (Cronbach's } \alpha=0.763 \text { ) }\end{array}$ & 61.2 & 947 & 990 \\
\hline 2.1 & $\begin{array}{l}\text { My supervisor/manager says a good word when he/she sees a job done according to } \\
\text { established patient safety procedures }\end{array}$ & 81 & 313.5 & 14.8 \\
\hline 2.2 & My supervisor/manager seriously considers staff suggestions for improving patient safety & 74 & 286 & 296 \\
\hline 2.3 & $\begin{array}{l}\text { Whenever pressure builds up, my supervisor/manager wants us to work faster, even if it } \\
\text { means taking shortcuts (R) }\end{array}$ & 45 & 176 & 214.9 \\
\hline \multirow[t]{2}{*}{2.4} & My supervisor/manager overlooks patient safety problems that happen over and over (R) & 44.5 & $17 \mid .5$ & 191.6 \\
\hline & Organizational learning - continuous improvement (Cronbach's $\alpha=0.7 \mid 2$ ) & 75.4 & 891.5 & 836.5 \\
\hline 1.6 & We are actively doing things to improve patient safety & 91.4 & 360.5 & 251 \\
\hline 1.9 & Mistakes have led to positive changes here & 85.6 & 232 & 267.2 \\
\hline \multirow[t]{2}{*}{1.13} & After we make changes to improve patient safety, we evaluate their effectiveness & 76 & 299 & 318.2 \\
\hline & Teamwork within units (Cronbach's $\alpha=0.650$ ) & 21.4 & 343.5 & 284.3 \\
\hline 1.1 & People support one another in this unit & 22.3 & 355 & 274.4 \\
\hline 1.3 & When a lot of work needs to be done quickly, we work together as a team to get the work done & 22 & 346.5 & 272 \\
\hline 1.4 & In this unit, people treat each other with respect & 24 & 355 & 260.2 \\
\hline \multirow[t]{2}{*}{1.11} & When one area in this unit gets really busy, other help out & 22 & 346.5 & 272.2 \\
\hline & Non-punitive response to error (Cronbach's $\alpha=0.602$ ) & 21.4 & 252 & 299.1 \\
\hline 1.8 & Staff feel like their mistakes are held against them (R) & 25.3 & 99.5 & 112.4 \\
\hline 1.12 & When an event is reported, it feels like the person is being written up, not the problem (R) & 23.5 & 93 & 107.5 \\
\hline \multirow[t]{2}{*}{1.16} & Staff worry that mistakes they make are kept in their personnel file $(\mathrm{R})$ & 15.3 & 59.5 & 64.3 \\
\hline & Staffing (Cronbach's $\alpha=0.103$ ) & 20 & 320 & 266.3 \\
\hline 1.2 & We have enough staff to handle the workload & 38.5 & 154 & 63.6 \\
\hline 1.5 & Staff in this unit work longer hours than is best for patient care (R) & 5 & 20 & 22.6 \\
\hline 1.7 & We use more agency/temporary staff than is best for patient care (R) & 24.1 & 94 & 82 \\
\hline \multirow[t]{2}{*}{1.14} & We work in "crisis mode" trying to do too much, too quickly (R) & 13.3 & 52 & 57.6 \\
\hline & Management support for patient safety (Cronbach's $\alpha=0.396$ ) & 63.7 & 745 & 760.8 \\
\hline 6.1 & Hospital management provides a work climate that promotes patient safety & 80.7 & 317.5 & 344.4 \\
\hline 6.8 & The actions of hospital management show that patient safety is a top priority & 72.6 & 281 & 253.1 \\
\hline \multirow[t]{2}{*}{6.9} & Hospital management seems interested in patient safety only after an adverse event happens & 37.8 & 146.5 & 163.3 \\
\hline & Teamwork across units (Cronbach's $\alpha=0.569$ ) & 57.1 & 889.1 & 959.5 \\
\hline 6.4 & There is good cooperation among hospital units that need to work together & 66.2 & 259.5 & 297.7 \\
\hline 6.10 & Hospital units work well together to provide the best care for patients & 70.8 & 272.5 & 296.2 \\
\hline 6.2 & Hospital units do not coordinate well with each other & 49.5 & 194.5 & 215 \\
\hline \multirow[t]{2}{*}{6.6} & It is often unpleasant to work with staff from other hospital units (R) & 42 & 163 & 191.6 \\
\hline & Handoffs and Transitions (Cronbach's $\alpha=0.767$ ) & 46 & 709 & 792 \\
\hline 6.3 & Things "fall between the cracks" when transferring patients from one unit to another (R) & 37.8 & 145.5 & 167.6 \\
\hline 6.5 & Important patient care information is often lost during shift changes (R) & 57.4 & 222 & 214.9 \\
\hline 6.7 & Problems often occur in the exchange of information across hospital units (R) & 41 & 158 & 200.8 \\
\hline \multirow[t]{2}{*}{6.11} & Shift changes are problematic for patients in this hospital (R) & 48 & 183.5 & 208.6 \\
\hline & Communication Openness (Cronbach's $\alpha=0.645$ ) & 45.9 & 542 & 332.3 \\
\hline 3.2 & Staff will freely speak up if they see something that may negatively affect patient care & 57.4 & 226.5 & 181.7 \\
\hline 3.4 & Staff feel free to question the decisions or actions of those with more authority & 40.4 & 157.5 & 109.6 \\
\hline \multirow[t]{2}{*}{3.6} & Staff are afraid to ask questions when something does not seem right (R) & 40 & 158 & 41 \\
\hline & Feedback and communication about error (Cronbach's $\alpha=0.729$ ) & 67 & 784.5 & 463.2 \\
\hline
\end{tabular}

(Continued) 
Table I (Continued).

\begin{tabular}{|c|c|c|c|c|}
\hline & & $\begin{array}{l}\text { Average \% Positive } \\
\text { Response }\end{array}$ & Average & SD \\
\hline 3.1 & We are given feedback about changes put into place based on event reports & 55.6 & 217.5 & 201.5 \\
\hline 3.3 & We are informed about errors that happen in this unit & 73.7 & 288.5 & 187.4 \\
\hline \multirow[t]{2}{*}{3.5} & In this unit, we discuss ways to prevent errors from happening again & 71.5 & 278.5 & 74.2 \\
\hline & Frequency of events reported (Cronbach's $\alpha=0.923$ ) & 65.2 & 752 & 213.5 \\
\hline 4.1 & $\begin{array}{l}\text { When a mistake is made, but is caught and corrected before affecting the patient, how } \\
\text { often is this reported? }\end{array}$ & 65.4 & 252 & 90.5 \\
\hline 4.2 & When a mistake is made, but has no potential to harm the patient, how often is this reported? & 60.7 & 234 & 72.1 \\
\hline 4.3 & When a mistake is made that could harm the patient, but does not, how often is this reported? & 69.5 & 266 & 51 \\
\hline
\end{tabular}

Notes: Adapted from Sorra and Nieva. ${ }^{12}$ The composite-level percentage of positive responses was calculated using the following formula: [number of positive responses to the items in the composite/total number of responses to the items (positive, neutral and negative) in the composite (excluding missing responses)] $\times$ I00. Negatively worded items that were reverse coded (R). The bold font in the numbers indicate the values for each dimension.

Abbreviation: SD, standard deviation.

reversed. The percentage of positive responses for each item was calculated by adding up the positive scores (agree and strongly agree responses). Composite-level scores were computed by adding up the positive scores of the items within a composite scale and dividing by the number of items of that composite scale (see Table 1).

Data normality was tested using the skewness and kurtosis criteria in SPSS. ${ }^{11}$ Pearson correlation coefficient was calculated for normally distributed variables, whereas Spearman correlation coefficient was used for nonnormally distributed variables. The total PSC score is normally distributed.

In addition, correlation analysis was conducted to assess the association between the study domains and average frequency of reported errors.

\section{Results}

\section{Testing for the Internal Consistency and Reliability}

Internal consistency of the instrument was measured by calculating Cronbach's coefficient $\alpha$ for the 12 composites; the values ranged between 0.103 and 0.923 (Table 1). According to the HSOPSC user's guide, a Cronbach's $\alpha$ 0.6 is acceptable, ${ }^{12}$ whereas Jenkinson et al (1994) suggest that values of $\alpha>0.5$ are acceptable. ${ }^{13}$ However, some scholars state that, when using psychological constructs, lower values of Cronbach's $\alpha$ are expected because of the diversity of the constructs being measured. ${ }^{14}$

\section{Participants}

In total, 805 responses were received; however, only 600 of the employees had completed the survey (67\% response rate). The response rate is sufficient to meet CBAHI and JCI's minimum requirement of $60 \%$ participation for HSOPSC.

\section{Demographic Characteristics of Participants}

Out of the 805 respondents, most of the participants were registered nurses $(\mathrm{n}=467,58 \%)$, followed by respiratory therapists $(\mathrm{n}=112,13 \%)$. Very few physicians responded to the questionnaire $(n=15,1.86 \%)$ and no responses recorded for Administration/Management staff.

Most of the participants were from intensive care unit $(\mathrm{n}=105,13 \%)$ and radiology department $(\mathrm{n}=102,13 \%)$, followed by surgery department $(\mathrm{n}=94,12 \%)$. In addition, more than $50 \%$ respondents indicated that they have direct interaction or contact with patients $(\mathrm{n}=555,69 \%)$ (Table 2).

The majority of participants had 1-5 years of work experience in their current specialty or profession $(n=$ $305,38 \%$ ). Regarding the participants' work history in the current hospital and unit, the majority indicated that they had 1-5 years of experience in the study teaching hospital $(\mathrm{n}=351,44 \%)$. Few had worked in the study setting for 21 years and more $(n=34,4 \%)$. The majority of participants indicated that they worked $40-59 \mathrm{~h}$ per week $(n=662,82 \%)$, and less than $2 \%(n=11)$ indicated that they worked $80 \mathrm{~h}$ and more per week (Table 3).

An overall PSC score was calculated by adding the scores of all domains. The average PSC score was 141.61 $(\mathrm{SD}=15.45)$. The overall PSC score differed significantly across different variables in the study. For instance, there is a significant difference in the overall PSC score across 
Table 2 Participants' Personal Information and Its Associations with Their Perceived Patient Safety Culture Score

\begin{tabular}{|c|c|c|c|c|}
\hline Variable & Categories & n (\%) & $\begin{array}{l}\text { Mean PSC } \\
\text { Score (SD) }\end{array}$ & $\begin{array}{l}\text { Test } \\
\text { (P-value) }\end{array}$ \\
\hline Department & $\begin{array}{l}\text { Many different hospital units/No specific Unit } \\
\text { Medicine (non-surgical) } \\
\text { Surgery } \\
\text { Obstetrics } \\
\text { Pediatrics } \\
\text { Emergency department } \\
\text { Intensive care unit (any type) } \\
\text { Psychiatry/mental health } \\
\text { Rehabilitation } \\
\text { Pharmacy } \\
\text { Laboratory } \\
\text { Radiology } \\
\text { Anesthesiology } \\
\text { Admin } \\
\text { Nursing } \\
\text { Maintenance } \\
\text { OR } \\
\text { OPD } \\
\text { Other, please specify } \\
\text { Missing }\end{array}$ & $\begin{array}{l}79(9.81) \\
0(0.00) \\
94(11.68) \\
28(3.48) \\
30(3.73) \\
68(8.45) \\
105(13.04) \\
25(3.11) \\
0(0.00) \\
16(1.99) \\
60(7.45) \\
102(12.67) \\
0(0.00) \\
20(2.48) \\
20(2.48) \\
32(3.98) \\
36(4.47) \\
26(3.23) \\
36(4.47) \\
28(3.48)\end{array}$ & 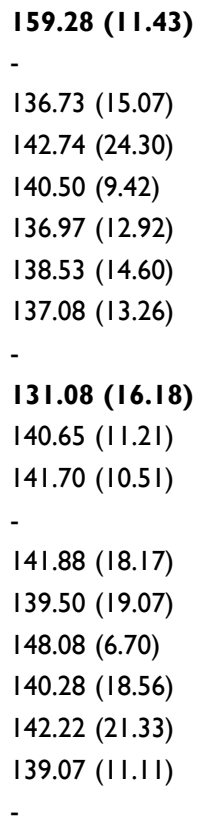 & $\begin{array}{l}f=10.011 \\
(<.000)\end{array}$ \\
\hline What is your staff position in this hospital & $\begin{array}{l}\text { Registered nurses } \\
\text { Physician assistant/Nurse practitioner } \\
\text { LVN/LPN } \\
\text { Patient care asst/Hospital aid/Care partner } \\
\text { Attending/Staff physician } \\
\text { Resident physician/Physician in training } \\
\text { Pharmacist } \\
\text { Dietician } \\
\text { Unit Assistant/Clerk/Secretary } \\
\text { Respiratory Therapist } \\
\text { Physical, occupational, or speech therapist } \\
\text { Technician (eg, EKG, lab, Rradiology) } \\
\text { Administration/Management } \\
\text { Other, please specify } \\
\text { Missing }\end{array}$ & $\begin{array}{l}467(58.01) \\
10(1.24) \\
16(1.99) \\
23(2.86) \\
15(1.86) \\
1(0.12) \\
3(0.37) \\
0(0.00) \\
0(0.00) \\
112(13.91) \\
29(3.60) \\
102(12.67) \\
0(0.00) \\
0(0.00) \\
27(3.35)\end{array}$ & $\begin{array}{l}140.70(14.25) \\
121.10(15.62) \\
148.86(14.70) \\
136.78(18.04) \\
132.50(\mid 6.03) \\
- \\
\mid 40.33(10.69) \\
- \\
- \\
\mid 36.44(9.10) \\
\mid 40.12(19.78) \\
\text { I56.98(13.27) } \\
- \\
- \\
-\end{array}$ & $\begin{array}{l}f=17.355 \\
(<.0001)\end{array}$ \\
\hline $\begin{array}{l}\text { In your staff position, do you typically have direct } \\
\text { interaction or contact with patients? }\end{array}$ & $\begin{array}{l}\text { Yes } \\
\text { No } \\
\text { Missing }\end{array}$ & $\begin{array}{l}555(68.94) \\
209(25.96) \\
4 I(5.09)\end{array}$ & $\begin{array}{l}\text { I39.80(|4.2) } \\
\text { I } 47.30(\text { I 7.5) } \\
-\end{array}$ & $\begin{array}{l}t=-5.088 \\
(<.0001)\end{array}$ \\
\hline
\end{tabular}

different departments $(f=10.011, P<0.0001)$. The highest overall score was for participants with no specific department $(\overline{\mathrm{x}}=159.28, \mathrm{SD}=11.43)$, followed by participants from the maintenance department $(\overline{\mathrm{x}}=148.08, \mathrm{SD}=6.70)$. Participants from the pharmacy department had the lowest PSC score $(\bar{x}=131.08, S D=16.18$; Table 2).

Physician assistants and nurse practitioners had significantly lower average PSC score $(\overline{\mathrm{x}}=121.10, \mathrm{SD}=15.62)$, than technicians, who had the highest PSC score $(\overline{\mathrm{x}}=156.98$,
$\mathrm{SD}=13.27 ; f=17.355, \mathrm{P}<0.0001)$. Furthermore, participants who had direct interaction with patients had significantly lower PSC scores $(\overline{\mathrm{x}}=139.80, \mathrm{SD}=14.2)$ than those who $\operatorname{did} \operatorname{not}(\overline{\mathrm{x}}=$ 147.30, $\mathrm{SD}=17.5 ; f=-5.088, \mathrm{P}<0.0001$; Table 2).

As shown in Table 3, participants' work experience in the study teaching hospital and their department/unit significantly influenced their PSC score $(f=2.964[P=0.012]$ and $f=2.618[P=0.023])$, respectively. Participants with less than 1 year of work experience in the study setting and 
Table 3 Participants Work Experience and Its Association with Their Perceived Patient Safety Culture Score

\begin{tabular}{|c|c|c|c|c|}
\hline Variable & Categories & n (\%) & $\begin{array}{l}\text { Mean PSC Score } \\
\text { (SD) }\end{array}$ & $\begin{array}{l}\text { Test } \\
\text { (P-value) }\end{array}$ \\
\hline How long have you worked in this hospital? & $\begin{array}{l}<1 \text { year } \\
1-5 \text { years } \\
6-10 \text { years } \\
11-15 \text { years } \\
16-20 \text { years } \\
\geq 21 \text { years } \\
\text { Missing }\end{array}$ & $\begin{array}{l}101(12.55) \\
351(43.60) \\
159(19.75) \\
89(11.06) \\
48(5.96) \\
34(4.22) \\
23(2.86)\end{array}$ & 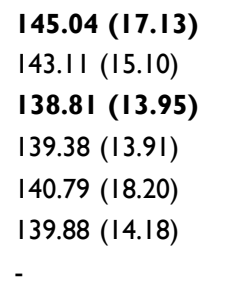 & $\begin{array}{l}f=2.964 \\
(0.012)\end{array}$ \\
\hline $\begin{array}{l}\text { How long have you worked in your current hospital work } \\
\text { area/unit? }\end{array}$ & $\begin{array}{l}<1 \text { year } \\
1-5 \text { years } \\
6-10 \text { years } \\
11-15 \text { years } \\
16-20 \text { years } \\
\geq 21 \text { years } \\
\text { Missing }\end{array}$ & $\begin{array}{l}95(11.80) \\
372(46.21) \\
157(19.50) \\
86(10.68) \\
41(5.09) \\
28(3.48) \\
26(3.23)\end{array}$ & 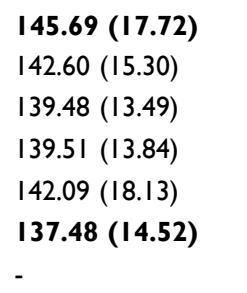 & $\begin{array}{l}f=2.618 \\
(0.023)\end{array}$ \\
\hline $\begin{array}{l}\text { How long have you worked in your current specialty or } \\
\text { profession? }\end{array}$ & $\begin{array}{l}<1 \text { year } \\
1-5 \text { years } \\
6-10 \text { years } \\
11-15 \text { years } \\
16-20 \text { years } \\
\geq 21 \text { years } \\
\text { Missing }\end{array}$ & $\begin{array}{l}29(3.60) \\
305(37.89) \\
214(26.58) \\
109(13.54) \\
60(7.45) \\
54(6.7 I) \\
34(4.22)\end{array}$ & $\begin{array}{l}\text { I } 44.96(17.89) \\
\text { I } 45.10(15.98) \\
\text { I39.05(14.28) } \\
\text { I39.52(I2.24) } \\
\text { I39.79(15.83) } \\
\text { I } 37.33(17.79) \\
-\end{array}$ & $\begin{array}{l}f=5.493 \\
(<.0001)\end{array}$ \\
\hline $\begin{array}{l}\text { Typically, how many hours per week do you work in this } \\
\text { hospital? }\end{array}$ & $\begin{array}{l}<20 \text { hours per week } \\
20-39 \text { hours per week } \\
40-59 \text { hours per week } \\
60-79 \text { hours per week } \\
80-99 \text { hours per week } \\
100 \text { hours per week or } \\
\text { more } \\
\text { Missing }\end{array}$ & $\begin{array}{l}6(0.75) \\
11(1.37) \\
662(82.24) \\
93(11.55) \\
6(0.75) \\
5(0.62) \\
22(2.73)\end{array}$ & 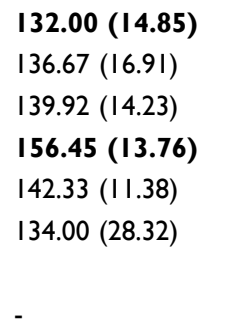 & $\begin{array}{l}f=20.868 \\
(<.0001)\end{array}$ \\
\hline
\end{tabular}

Notes: The bold font in the numbers indicate a significant association. Adapted from Sorra and Nieva. ${ }^{12}$.

Abbreviations: $\mathrm{n}$, sample size; SD, standard deviation; $f, f$-value.

their current department had the highest mean PSC score $(\overline{\mathrm{x}}=$ 145). The participants' work experience significantly affected their total PSC score $(f=5.493, \mathrm{P}<0.0001)$; participants with less work experience had a higher average PSC score (Table 3). Total weekly working hours also significantly influenced the total PSC score $(f=20.868, \mathrm{P}<$ 0.0001); participants who worked 60 to $79 \mathrm{~h}$ per week had the highest average PSC score $(\overline{\mathrm{x}}=156.45, \mathrm{SD}=13.76)$, whereas participants who worked less than $20 \mathrm{~h}$ per week had the lowest average PSC score ( $\overline{\mathrm{x}}=132, \mathrm{SD}=14.85$; Table 3$)$.

\section{Composites and Outcomes}

Table 4 shows the participants' detailed responses to scale items. The safety culture dimensions with the highest positive score measured organizational learning - continuous improvement (75.4\%), feedback and communication about error (67\%), and frequency of events reported (65.2\%). Dimensions scoring the lowest were staffing (20\%), teamwork within units $(21.4 \%)$, and non-punitive response to error (21.4\%). Figure 1 contains PSC benchmarking between KFTH and Agency for Healthcare Research and Quality (AHRQ) in the year 2018. ${ }^{15}$ Dimensions with lowest scores in AHRQ are staffing (54\%), non-punitive culture (45\%), and handoff and transition (48\%). However, in PSC benchmarking between KFTH and AHRQ-2018, the KFUH is considerably below the benchmark, especially in two dimensions of non-punitive response to error (21.4\%) and staffing $(20 \%){ }^{15}$

Moreover, around $42 \%$ of respondents reported not completing any event reports in the past 12 months (Table 5), 
Table 4 Detailed Responses of Scale Items

\begin{tabular}{|c|c|c|c|c|c|c|}
\hline Composite & Question & $\begin{array}{l}\text { Strongly } \\
\text { Agree }\end{array}$ & Agree & Neither & Disagree & $\begin{array}{l}\text { Strongly } \\
\text { Disagree }\end{array}$ \\
\hline \multirow[t]{4}{*}{$\begin{array}{l}\text { I. Overall perceptions of } \\
\text { patient safety }\end{array}$} & $\begin{array}{l}\text { It is just by chance that more serious mistakes do not } \\
\text { happen around here }\end{array}$ & $25(3.1)$ & $221(27.5)$ & $224(27.8)$ & $270(33.5)$ & $40(5.0)$ \\
\hline & $\begin{array}{l}\text { Patient safety is never sacrificed to get more work } \\
\text { done }\end{array}$ & $91(11.3)$ & $445(55.3)$ & $167(20.7)$ & $71(8.8)$ & $10(1.2)$ \\
\hline & We have patient safety problems in this unit & $61(7.6)$ & $353(43.9)$ & $|3|(\mid 6.3)$ & $183(22.7)$ & $32(4)$ \\
\hline & $\begin{array}{l}\text { Our procedures and systems are good at preventing } \\
\text { errors from happening }\end{array}$ & $50(6.2)$ & $525(65.2)$ & $149(18.5)$ & $46(5.7)$ & $17(2.1)$ \\
\hline \multirow[t]{4}{*}{$\begin{array}{l}\text { 2. Supervisor/manager } \\
\text { expectations and actions } \\
\text { promoting patient safety }\end{array}$} & $\begin{array}{l}\text { My supervisor/manager says a good word when he/ } \\
\text { she sees a job done according to established patient } \\
\text { safety procedures }\end{array}$ & $104(12.9)$ & $523(65)$ & $106(13.2)$ & $31(3.9)$ & $10(1.2)$ \\
\hline & $\begin{array}{l}\text { My supervisor/manager seriously considers staff } \\
\text { suggestions for improving patient safety }\end{array}$ & $83(10.3)$ & $489(60.7)$ & $161(20)$ & $23(2.9)$ & $17(2.1)$ \\
\hline & $\begin{array}{l}\text { Whenever pressure builds up, my supervisor/ } \\
\text { manager wants us to work faster, even if it means } \\
\text { taking shortcuts }\end{array}$ & $24(3.0)$ & $328(40.7)$ & $215(26.7)$ & $175(21.7)$ & $34(4.2)$ \\
\hline & $\begin{array}{l}\text { My supervisor/manager overlooks patient safety } \\
\text { problems that happen over and over }\end{array}$ & $36(4.5)$ & $307(38.1)$ & $166(20.6)$ & $231(28.7)$ & $30(3.7)$ \\
\hline \multirow{3}{*}{$\begin{array}{l}\text { 3. Organizational learning - } \\
\text { continuous improvement }\end{array}$} & We are actively doing things to improve patient safety & $183(22.7)$ & $538(66.8)$ & $45(5.6)$ & $17(2.1)$ & $6(0.7)$ \\
\hline & Mistakes have led to positive changes here & $43(5.3)$ & $421(52.3)$ & $24 \mid(29.9)$ & $74(9.2)$ & $13(1.6)$ \\
\hline & $\begin{array}{l}\text { After we make changes to improve patient safety, we } \\
\text { evaluate their effectiveness }\end{array}$ & $74(9.2)$ & $524(65.1)$ & $143(17.8)$ & $35(4.3)$ & $10(1.2)$ \\
\hline \multirow[t]{4}{*}{ 4. Teamwork within units } & People support one another in this unit & $16 \mid(20)$ & $549(68.2)$ & $66(8.2)$ & $18(2.2)$ & $10(1.2)$ \\
\hline & $\begin{array}{l}\text { When a lot of work needs to be done quickly, we work } \\
\text { together as a team to get the work done }\end{array}$ & $154(19.1)$ & $539(67)$ & $76(9.4)$ & $23(2.9)$ & $6(0.7)$ \\
\hline & In this unit, people treat each other with respect & $17 \mid(21.2)$ & $539(67)$ & $68(8.4)$ & $21(2.6)$ & $4(0.5)$ \\
\hline & $\begin{array}{l}\text { When one area in this unit gets really busy, other } \\
\text { help out }\end{array}$ & $69(8.6)$ & $401(49.8)$ & $228(28.3)$ & $70(8.7)$ & $21(2.6)$ \\
\hline \multirow{3}{*}{$\begin{array}{l}\text { 5. Non-punitive response to } \\
\text { error }\end{array}$} & Staff feel like their mistakes are held against them & $20(2.5)$ & $179(22.2)$ & $284(35.3)$ & $242(30.1)$ & $62(7.7)$ \\
\hline & $\begin{array}{l}\text { When an event is reported, it feels like the person is } \\
\text { being written up, not the problem }\end{array}$ & $17(2.1)$ & $169(21.0)$ & $250(31.1)$ & $302(37.5)$ & $54(6.7)$ \\
\hline & $\begin{array}{l}\text { Staff worry that mistakes they make are kept in their } \\
\text { personnel file }\end{array}$ & $14(1.7)$ & $105(13)$ & $202(25.1)$ & $359(44.6)$ & $98(12.2)$ \\
\hline \multirow[t]{4}{*}{ 6. Staffing } & We have enough staff to handle the workload & $64(8)$ & $295(36.6)$ & $134(16.6)$ & $199(24.7)$ & $109(13.5)$ \\
\hline & $\begin{array}{l}\text { We work in "crisis mode" trying to do too much, } \\
\text { too quickly }\end{array}$ & II (1.4) & $93(11.6)$ & $193(24.0)$ & $404(50.2)$ & $81(10.1)$ \\
\hline & $\begin{array}{l}\text { Staff in this unit work longer hours than is best for } \\
\text { patient care }\end{array}$ & $4(0.5)$ & $36(4.5)$ & $110(13.7)$ & $490(60.9)$ & $160(19.9)$ \\
\hline & $\begin{array}{l}\text { We use more agency/temporary staff than is best for } \\
\text { patient care }\end{array}$ & $36(4.5)$ & $152(18.9)$ & $243(30.2)$ & $302(37.5)$ & $48(6.0)$ \\
\hline
\end{tabular}

(Continued) 
Table 4 (Continued).

\begin{tabular}{|c|c|c|c|c|c|c|}
\hline Composite & Question & $\begin{array}{l}\text { Strongly } \\
\text { Agree }\end{array}$ & Agree & Neither & Disagree & $\begin{array}{l}\text { Strongly } \\
\text { Disagree }\end{array}$ \\
\hline \multirow[t]{3}{*}{$\begin{array}{l}\text { I. Management Support for } \\
\text { patient safety }\end{array}$} & $\begin{array}{l}\text { Hospital management provides a work climate that } \\
\text { promotes patient safety }\end{array}$ & $74(9.2)$ & $561(69.7)$ & $110(13.7)$ & $30(3.7)$ & II (1.4) \\
\hline & $\begin{array}{l}\text { The actions of hospital management show that } \\
\text { patient safety is a top priority }\end{array}$ & $102(12.7)$ & $460(57.1)$ & $147(18.3)$ & $52(6.5)$ & $13(1.6)$ \\
\hline & $\begin{array}{l}\text { Hospital management seems interested in patient } \\
\text { safety only after an adverse event happens }\end{array}$ & $31(3.9)$ & $262(32.5)$ & $230(28.6)$ & $203(25.2)$ & $49(6.1)$ \\
\hline \multirow[t]{4}{*}{ 2. Teamwork across units } & $\begin{array}{l}\text { There is good cooperation among hospital units that } \\
\text { need to work together }\end{array}$ & $49(6.1)$ & $470(58.4)$ & $189(23.5)$ & $57(7.1)$ & $19(2.4)$ \\
\hline & $\begin{array}{l}\text { Hospital units work well together to provide the } \\
\text { best care for patients }\end{array}$ & $106(13.2)$ & $439(54.5)$ & $174(21.6)$ & $44(5.5)$ & $7(0.9)$ \\
\hline & $\begin{array}{l}\text { Hospital units do not coordinate well with each } \\
\text { other }\end{array}$ & $29(3.6)$ & $360(44.7)$ & $207(25.7)$ & $156(19.4)$ & $34(4.2)$ \\
\hline & $\begin{array}{l}\text { It is often unpleasant to work with staff from other } \\
\text { hospital units }\end{array}$ & $27(3.4)$ & $299(37.1)$ & $289(35.9)$ & $128(15.9)$ & $33(4.1)$ \\
\hline \multirow[t]{4}{*}{ 3. Handoffs and transitions } & $\begin{array}{l}\text { Things "fall between the cracks" when transferring } \\
\text { patients from one unit to another }\end{array}$ & $27(3.4)$ & $264(32.8)$ & $283(35.2)$ & $163(20.2)$ & $32(4.0)$ \\
\hline & $\begin{array}{l}\text { Important patient care information is often lost } \\
\text { during shift changes }\end{array}$ & $70(8.7)$ & $374(46.5)$ & $175(2 \mid .7)$ & $139(17.3)$ & $15(1.9)$ \\
\hline & $\begin{array}{l}\text { Problems often occur in the exchange of information } \\
\text { across hospital units }\end{array}$ & $16(2)$ & $300(37.3)$ & $262(32.5)$ & $161(20)$ & $32(4)$ \\
\hline & $\begin{array}{l}\text { Shift changes are problematic for patients in this } \\
\text { hospital }\end{array}$ & $36(4.5)$ & $33 I(4 I . I)$ & $242(30.1)$ & $118(14.7)$ & $39(4.8)$ \\
\hline \multirow[t]{3}{*}{ 4. Communication openness } & $\begin{array}{l}\text { Staff will freely speak up if they see something that } \\
\text { may negatively affect patient care }\end{array}$ & $98(12.2)$ & $355(44.1)$ & $247(30.7)$ & $67(8.3)$ & $22(2.7)$ \\
\hline & $\begin{array}{l}\text { Staff feel free to question the decisions or actions of } \\
\text { those with more authority }\end{array}$ & $80(9.9)$ & $235(29.2)$ & 271 (33.7) & $119(15)$ & $75(9.3)$ \\
\hline & $\begin{array}{l}\text { Staff are afraid to ask questions when something } \\
\text { does not seem right }\end{array}$ & $129(16.0)$ & $187(23.2)$ & $302(37.5)$ & $126(15.7)$ & $46(5.7)$ \\
\hline \multirow[t]{3}{*}{$\begin{array}{l}\text { 5. Feedback and } \\
\text { communication about error }\end{array}$} & $\begin{array}{l}\text { We are given feedback about changes put into place } \\
\text { based on event reports }\end{array}$ & $75(9.3)$ & $360(44.7)$ & $289(35.9)$ & $47(5.8)$ & $12(1.5)$ \\
\hline & $\begin{array}{l}\text { We are informed about errors that happen in this } \\
\text { unit }\end{array}$ & $156(19.4)$ & 421 (52.3) & $153(19)$ & $46(5.7)$ & $7(0.9)$ \\
\hline & $\begin{array}{l}\text { In this unit, we discuss ways to prevent errors from } \\
\text { happening again }\end{array}$ & $226(28.1)$ & $33 I(4 I . I)$ & $182(22.6)$ & $31(3.9)$ & (I.I) \\
\hline \multirow[t]{3}{*}{$\begin{array}{l}\text { 6. Frequency of events } \\
\text { reported }\end{array}$} & $\begin{array}{l}\text { When a mistake is made, but is caught and corrected } \\
\text { before affecting the patient, how often is this reported? }\end{array}$ & $188(23.4)$ & $316(39.3)$ & 177 (22) & $71(8.8)$ & $19(2.4)$ \\
\hline & $\begin{array}{l}\text { When a mistake is made, but has no potential to } \\
\text { harm the patient, how often is this reported? }\end{array}$ & $183(22.7)$ & $285(35.4)$ & $213(26.5)$ & $65(8.1)$ & $25(3.1)$ \\
\hline & $\begin{array}{l}\text { When a mistake is made that could harm the patient, } \\
\text { but does not, how often is this reported? }\end{array}$ & $230(28.6)$ & $302(37.5)$ & $157(19.5)$ & $50(6.2)$ & $27(3.4)$ \\
\hline
\end{tabular}

Notes: Adapted from Sorra and Nieva. ${ }^{12 .}$ 
Frequency of Events Reported

Feedback \& Communication about Error

Communication Openness

Handoffs \& Transitions

Teamwork Across Units

Management Support for patient Safety

Staffing

Non-punitive Response to Error

Teamwork Within Units

Organizational Learning- Continuous improvement

Supv/Mgr Expectations \& Actions Promoting Patient safety

Overall Perceptions of patient safety

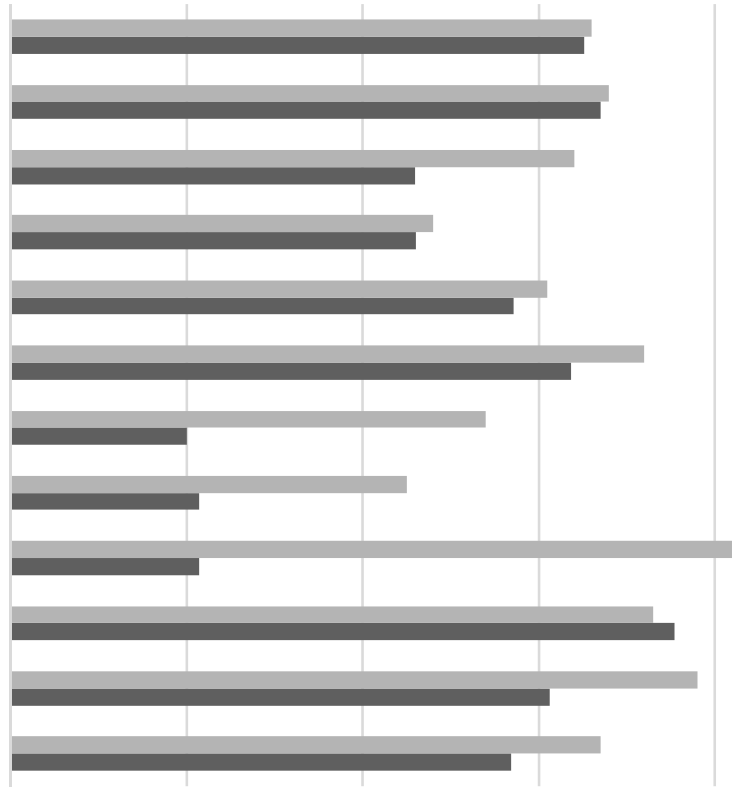

0

20

40

60

80

\section{$\square$ AHRQ $\square$ KFUH}

Figure I PSC benchmarking between KFUH and AHRQ-20I8.

Notes: Data from Sorra and Nieva. ${ }^{12}$

and approximately $80 \%$ assigned the hospital an "excel-

lent/very good" patient safety culture grade. (Figure 2).

In addition, correlation analysis was conducted to assess the association between the study domains and average frequency of reported errors (Table 6). Correlations between the study domains and average frequency of reported errors were weak (correlation coefficient $<0.5$ ) but were statistically significant.

\section{Discussion}

The present study employed the HSOPSC tool to investigate the level of PSC at KFUH. Survey respondents were

Table 5 Number of Events Reported During the Year Preceding the Survey

\begin{tabular}{|l|r|l|}
\hline & Percentage (\%) & Count (N) \\
\hline No event reports & 41 & 245 \\
I-2 Event reports & 28 & 170 \\
$3-5$ Event reports & 17 & 99 \\
6-10 Event reports & 9 & 55 \\
II-20 Event reports & 2 & 14 \\
2I Event reports or more & 3 & 17 \\
Total & 100 & 600 \\
\hline
\end{tabular}

Abbreviation: $\mathrm{N}$, sample size.

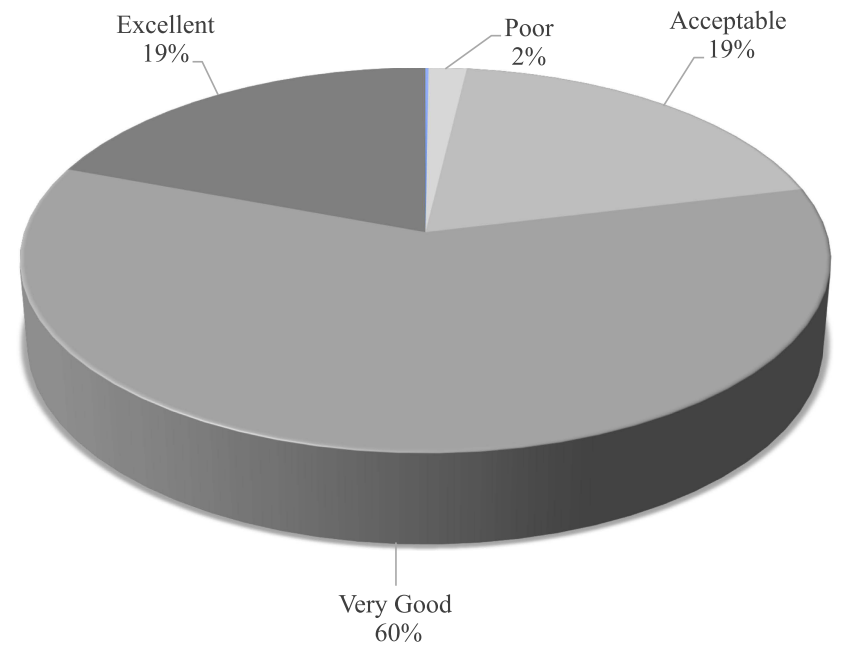

Figure 2 Overall grade of patient safety culture.

primarily employed in radiology, intensive care, and surgical units. The composites with the highest positive ratings were organizational learning - continuous improvement, feedback and communication about error, and frequency of events reported, and management support for patient safety. Whereas those with the lowest ratings included teamwork within units, non-punitive response to error, and staffing. Approximately 50\% respondents reported not completing any event reports in 
Table 6 Correlation Assessment Between the Domains in the Study and the Mean Frequency of Errors Reported

\begin{tabular}{|c|c|c|c|c|c|c|c|}
\hline & Mean (SD) & Median & Skewness & Kurtosis & $\begin{array}{l}\text { Mean } \\
\text { Frequency } \\
\text { of Errors } \\
\text { Reported } \\
\text { (SD) }\end{array}$ & $\begin{array}{c}\text { Pearson } \\
\text { Correlation } \\
\text { with Total } \\
\text { PSC Score } \\
r \text { (p-value) }\end{array}$ & $\begin{array}{c}\text { Spearman } \\
\text { Correlation } \\
\text { with Total } \\
\text { PSC Score } \rho \\
\text { (p-value) }\end{array}$ \\
\hline Communication openness & $6.55(1.96)$ & - & -0.772 & 1.034 & $10.81(3.53)$ & $0.314^{* *}(<.000)$ & - \\
\hline $\begin{array}{l}\text { Feedback and communication about } \\
\text { error }\end{array}$ & - & 12 & -1.578 & 4.598 & & - & $0.375^{* *}(<.000)$ \\
\hline Handoffs and transitions & $6.59(1.58)$ & - & -0.41 & -0.26 & & $0.106 * *(0.003)$ & - \\
\hline $\begin{array}{l}\text { Management support for patient } \\
\text { safety }\end{array}$ & - & 8 & -0.948 & 2.456 & & - & $0.234^{* *}(<.000)$ \\
\hline Non-punitive response to error & $5.13(1.64)$ & - & -0.399 & 0.85 & & $0.157^{* *}(<.000)$ & - \\
\hline $\begin{array}{l}\text { Organizational learning - continuous } \\
\text { improvement }\end{array}$ & - & 8 & -1.786 & 5.633 & & - & $0.314^{* *}(<.000)$ \\
\hline Staffing & $6.11(1.39)$ & - & 0.01 & -0.62 & & $0.149 * *(<.000)$ & - \\
\hline $\begin{array}{l}\text { Supervisor/manager expectations and } \\
\text { actions promoting patient safety }\end{array}$ & - & 11 & -2.146 & 6.667 & & - & $0.182^{* *}(<.000)$ \\
\hline Teamwork across units & $3.77(0.79)$ & - & -0.717 & 0.881 & & $0.191 * *(<.000)$ & - \\
\hline Teamwork within units & - & 12 & -1.499 & 6.107 & & - & $0.106 * *(0.003)$ \\
\hline Overall perceptions of patient safety & - & 7 & -1.256 & 2.609 & & - & $0.079 *(0.025)$ \\
\hline Total patient safety culture score & $94.87(10.76)$ & 95 & -0.462 & 0.982 & & $0.452^{* *}(<.000)$ & - \\
\hline
\end{tabular}

Notes: Adapted from Sorra and Nieva. ${ }^{12} * *$ Significance with $\mathrm{p}$-value $<0.000$, * significance with $\mathrm{p}$-value $<0.05$.

Abbreviations: SD, standard deviation.

the past 12 months, and most assigned the hospital an "excellent/very good" patient safety grade. Similarly, dimensions with the lowest scores in AHRQ are staffing, non-punitive culture, and handoff and transition. However, in PSC benchmarking between KFTH and AHRQ-2018, ${ }^{15}$ the KFUH is far below the benchmark, especially in two dimensions of non-punitive response to error and staffing.

Similarly, in 2017, the Saudi Patient Safety Centre (SPSC) launched the national hospital survey on patient safety culture. The first two cycles were conducted in 2018 and 2019. The results of both cycles indicated three dimensions of safety culture that need improvement, namely, non-punitive response to error, staffing, and communication openness. ${ }^{16,17}$ The current study found similar results; that is, both non-punitive response to error and staffing were two of the main weak safety culture dimensions at KFUH and KSA in general.

The results from the study are consistent with findings from research studies conducted in Iran and Saudi Arabia, which found that punitive attitudes towards error reports not only hindered event reporting but also demonstrated flaws in policy and communication procedures. ${ }^{7,8}$ The present study's findings are also corroborated by a survey of hospitals in Sweden and Tunisia, which found the existence of a punitive culture. ${ }^{18}$ Punitive culture can leave critical patient safety unaddressed due to underreporting as a result of a fear of punishment. Creating a non-punitive culture requires complex interventions and continuous effort until this culture is completely integrated into KFUH's culture. Furthermore, cultural change takes time; safety culture should be continuously measured, areas of improvement should be understood, and actions should be taken to further improve the culture. ${ }^{19}$

This finding is also consistent with a systematic review of 33 studies that examined safety culture by using HSOPSC among healthcare practitioners from 22 countries in different regions. ${ }^{20}$ This result indicates that punitive culture and staffing issues are common problems facing hospitals in different countries worldwide. In nearly $70 \%$ of the studies included in the systematic review, nonpunitive response to error scored weak. ${ }^{20}$

In addition, many participants reported understaffing in their units and working longer hours, which negatively affecting patients' care. The perceived inadequacy of staffing influences how healthcare practitioners perceive and perform their work, affecting the quality and safety of healthcare services. Scholars suggest that medical practitioners with a high workload and in understaffed hospitals usually suffer from stress, anxiety, depression, and lack of sleep, which may cause lapses in judgment and 
significantly increase the risk of catastrophic medical errors. $^{21-23}$ Decision makers cannot base their decisions solely on a perceived adequacy of staffing. Understanding what shapes healthcare practitioners' perception of the adequacy of staffing is important to tailor strategies and take actions appropriate to the context of KFUH. The perceived adequacy of staffing can be influenced by several factors other than the actual shortage of staff. These factors include poor organization and coordination of work, underutilization of technologies that can reduce the burden of patient care, and patient characteristics. ${ }^{24,25}$

In contrast to the results of the Saudi National Hospital survey on patient safety culture in 2018 and $2019,{ }^{16,17}$ the management support for patient safety and teamwork within units were identified as weak dimensions of safety culture at KFUH. A possible reason for this inconsistency is that teaching hospitals have teams with variety of experiences, which can lead to the "lack of shared mental models", where team members do not have a common understanding about required task and/or patient care result in poor teamwork. ${ }^{26}$ In addition, many studies reported communication problems with junior doctors. Bullying and undermining behaviour was also reported by nurses and interns at teaching hospitals. ${ }^{26-28}$ These factors might result in failure teamwork, which indeed was associated with higher levels of risk to patients. ${ }^{26}$

Respondents voiced concerns about teamwork practice within the units they worked in, which indeed affects PSC. Many respondents reported low positive scores for teamwork in their unit, including the level of respect among staff in their unit and the support people receive from each other. This finding is consistent with a study conducted in Riyadh in KSA, which revealed low positive scores for teamwork. ${ }^{4}$ However, in PSC benchmarking between KFTH and AHRQ-2018, ${ }^{15}$ the KFUH is far below the benchmark in the 'teamwork within units' dimension.

Hospitals in KSA should pay special attention to teamwork because previous studies indicate that poor teamwork by one team member, whether actual or perceived, is sufficient to cause a negative change in the team dynamic. $^{29}$ In contrast, effective teamwork and communication has numerous benefits such as fewer and shorter delays in care and improved staff morale, job satisfaction, and efficiency. ${ }^{29}$ This is especially important in intensive care units, where most of the respondents of the present study currently work. Thus, it is crucial to identify the reasons behind health practitioners' poor perception of teamwork and implement corrective interventions to enhance teamwork in Saudi hospitals.

Findings from the analysis demonstrated that KFUH possesses various areas of strength in PSC. Respondents reported that the management support of patient safety is high. Many respondents reported that the hospital management considered patient safety a top priority. This is consistent with the results of a systematic review that explored the status of PSC in Arab countries and stated that patient safety is a top priority in health policy agenda in Arab countries. ${ }^{30}$ Few of the respondents reported that the hospital management intervenes after an adverse event occurs. This is inconsistent with the findings of a previous study conducted in KSA. ${ }^{4}$

Communication and openness about error dimension, however, was one of the strong dimensions of safety culture at KFUH. This result is inconsistent with the National Saudi HSOPSC results ${ }^{16,17}$ as well as a study conducted on a teaching hospital in Riyadh city. ${ }^{31}$ Continuous improvements are necessary, especially with regard to continuous communication about errors and reporting events in order to learn from others' mistakes, which will likely reduce potential hazards.

Moreover, although the perceived frequency of errors reported is above average, the actual number of errors reported is significantly low. Approximately half of the study respondents reported not completing any event reports in the past 12 months. Thus, developing a nonpunitive culture is crucial to positively influence the practice of error reporting.

The present study had certain strengths: it used a wellvalidated questionnaire that has been widely used in many studies, including that conducted in $\mathrm{KSA}^{31}$ with a large sample size, which yielded valid results. However, the study also had several limitations. First, the study adopted a cross-sectional design, which analyzed PSC at one point in time. Therefore, it does not capture the effects of ongoing monthly efforts at KFUH to improve patient safety. Furthermore, none of the study respondents were from the hospital management; thus, the findings may not reflect the whole picture of PSC in the study setting. There was also variation in the respondents' current position; the majority of the respondents were nurses. Thus, future efforts should concentrate on encouraging the participation of other healthcare practitioners and administrative staff by implementing a condensed version of the questionnaire in order to increase the response rate from respondents with tight schedule. Future qualitative studies are also needed to 
dig deeper into the reasons behind lack of responses from managers and doctors.

The study was also limited by language barriers; the HSOPSC survey is published in English, which limited the understanding of some employees. Future efforts should focus on administering the questionnaire in different languages - especially Arabic, as it is the main language in KSA - and consolidating related questions to reduce the length of the questionnaire. It is also required to conduct the questionnaire in multiple teaching hospitals in KSA in order to enhance the generalizability of results across the KSA.

\section{Conclusions}

The present study offers an overall assessment of PSC perceptions among healthcare workers at KFUH by using the HSOPSC, which is one of the most commonly used tools to assess PSC. Although most respondents reported very good/excellent patient safety score, with some areas of strengths such as feedback and communication about error and frequency of events reported, they also reported significant weaknesses in some HSOPSC composites, mainly teamwork within units, non-punitive culture, and staffing.

Investing in practices that will strengthen patient safety is crucial for KFUH. Additionally, there is a need to include safety training in the hospital's learning programs with an emphasis on teamwork. Continuous training and the adoption of policies, governance, and open reporting structure are also necessary. There is also a need to divide the assessment period and use bi-annual PSC assessments aimed at identifying areas for improvement in order to implement relevant interventions.

Results from the present study offer valuable insights into the challenges faced by a teaching hospital when integrating a culture of patient safety. The findings may facilitate policy changes aimed at improving the processes and systems that govern safety procedures in hospitals. To initiate safety improvements at KFUH, the hospital needs to mobilize resources to increase the number of employees, create policies to encourage non-punitive reporting, and develop clear communication channels to not only increase teamwork across departments but also streamline transfer processes.

\section{Abbreviations}

CBAHI, Saudi Central Board for Accreditation of Healthcare Institutions; JCI, Joint Commission International; KFHU,
King Fahd Hospital of the University; PSC, patient safety culture; HSOPSC, Hospital Survey on Patient Safety Culture; AHRQ, Agency for Healthcare Research and Quality; WHO, World Health Organization; IRB, Institute Review Board.

\section{Data Sharing Statement}

The research study data are available upon request from authors.

\section{Ethical Approval and Informed Consent}

Ethical approval was obtained from the Institutional review board at Imam Abdulrahman Bin Faisal University [IRB-PGS-2019-03-389]. Written informed consent was obtained at the beginning of the survey.

\section{Funding}

This research did not receive any specific grant from funding agencies in the public, commercial, or not-forprofit sectors.

\section{Disclosure}

No potential conflict of interest was reported by the authors.

\section{References}

1. AbuAlRub RF, Abu Alhijaa EH. The impact of educational interventions on enhancing perceptions of patient safety culture among Jordanian senior nurses. Nurs Forum. 2014;49(2):139-150.

2. Lawati MHA, Dennis S, Short SD, et al. Patient safety and safety culture in primary health care: a systematic review. BMC Fam Pract. 2018;191(1):104.

3. Ginsburg L, Oore DG. Patient safety climate strength: a concept that requires more attention. BMJ Qual Saf. 2016;25(9):680-687.

4. Alahmadi HA. Assessment of patient safety culture in Saudi Arabian hospitals. BMJ Qual Saf. 2010;19(5):e17.

5. Hickner J, Smith SA, Yount N, et al. Differing perceptions of safety culture across job roles in the ambulatory setting: analysis of the AHRQ medical office survey on patient safety culture. BMJ Qual Saf. 2016;25(8):588-594.

6. Tsao K, Browne M. Culture of safety: a foundation for patient care. Semin Pediatr Surg. 2015;24(6):283-328.

7. Farokhzadian J, Nayeri ND, Borhani F. The long way ahead to achieve an effective patient safety culture: challenges perceived by nurses. BMC Health Serv Res. 2018;18(1):654.

8. Ferrer M, Santa R, Medhekar A, et al. Drivers of hospital safety culture quality in emerging economies: the case of Saudi Arabia. IJPQM. 2018;23(3):369-384.

9. CBAHI. National hospital standards; 2015. Available from https:// portal.cbahi.gov.sa/english/accreditation-programs/hospitalaccreditation-program. Accessed June 26, 2020.

10. IBM Corp. IBM SPSS Statistics for Macintosh. 25th ed. Armonk: IBM Corp; 2017. 
11. Ghasemi A, Zahediasl S. Normality tests for statistical analysis: a guide for non-statisticians. Int J Endocrinol Metab. 2012;10(2):486-489.

12. Sorra JS, Nieva VF. Hospital Survey on Patient Safety Culture, AHRQ Publication No. 04-0041. Rockville: Agency for Healthcare Research and Quality; 2004. Available from: https://proqualis.net/ sites/proqualis.net/files/User\%20guide\%20HSOPSC.pdf. Accessed September 3, 2021.

13. Jenkinson C, Wright L, Coulter A. Criterion validity and reliability of the SF-36 in a population sample. Qual Life Res. 1994;3(1):7-12.

14. Field A. Discovering Statistics Using IBM SPSS Statistics. 4th ed. Los Angeles: Sage; 2013.

15. AHRQ. Hospital Survey on Patient Safety Culture 2018 User Database Report. Available from:: https://www.ahrq.gov/sites/ default/files/wysiwyg/sops/quality-patient-safety/patientsafetyculture/ 2018hospitalsopsreport.pdf. Accessed March 1, 2021.

16. Saudi Patient Safety Center. Hospital Survey on Patient Safety Culture Cycle 1. Riyadh: Saudi Patient Safety Center; 2018. Available from: https://spsc.gov.sa/Arabic/SiteAssets/Pages/national-recommendations /national-recommendations.pdf. Accessed March 26, 2021.

17. Saudi Patient Safety Center. The Release of HSOPSC - Facility Report for 2nd Cycle 2019. Riyadh: Saudi Patient Safety Center; 2020a. Available from: https://www.spsc.gov.sa/English/News/ Pages/news37.aspx. Accessed March 26, 2021.

18. Ali H, Ibrahem SZ, Al Mudaf B, et al. Baseline assessment of patient safety culture in public hospitals in Kuwait. BMC Health Serv Res. 2018;18(1):158.

19. Singer SJ, Dunham KM, Bowen JD, et al. Lessons in safety climate and safety practices from a California Hospital Consortium. In: In singer SJ, Dunham KM, et al. editors. Advances in Patient Safety: From Research to Implementation. Rockville: Agency of Healthcare Research and Quality; 2005:411-424.

20. Tartaglia Reis C, Paiva SG, Sousa P. The patient safety culture: a systematic review by characteristics of Hospital survey on patient safety culture dimensions. Int J Qual Health Care. 2018;30(9):660-677.
21. Blendon RJ, DesRoches CM, Brodie M, et al. Views of practicing physicians and the public on medical errors. NEJM. 2002;347 (24):1933-1940.

22. Kunaviktikul W, Wichaikhum O. Nantsupawat, A et al. Nurses' extended work hours: patient, nurse and organizational outcomes. Int Nurs Rev. 2015;62(3):386-393.

23. Shanafelt TD, Balch CM, Bechamps G, et al. Burnout and medical errors among American surgeons. Ann Surg. 2010;251(6):9 95-1000.

24. Mark BA. What explains nurses' perceptions of staffing adequacy? J Nurs Adm. 2002;32(5):234-242.

25. Nelson BA. Healthcare team members' perception of staffing adequacy in a comprehensive cancer center. Oncol Nurs Forum. 2011;38 (1):52-59.

26. O'connor P, O'Dea A, Lydon S, et al. A mixed-methods study of the causes and impact of poor teamwork between junior doctors and nurses. Int J Qual Health Care. 2016;28(3):339-345.

27. Quine L. Workplace bullying in junior doctors: questionnaire survey. Br Med J. 2002;324:878-879.

28. Sheehan M, McCabe TJ Executive summary: INMO workplace bullying survey findings over the past four years (2010-2014). Available from: www.inmo.ie/tempDocs/Executive\%20Summary\%20Bullying. pdf. Accessed May 20, 2015.

29. Sexton JB, Thomas EJ, Helmreich RL. Error, stress, and teamwork in medicine and aviation: cross sectional surveys. BMJ. 2000;320 (7237):745-749.

30. Elmontsri M, Almashrafi A, Banarsee R, Majeed A. Status of patient safety culture in Arab countries: a systematic review. BMJ Open. 2017;7(2):e013487.

31. El-Jardali F, Sheikh F, Garcia NA, et al. Patient safety culture in a large teaching hospital in Riyadh: baseline assessment, comparative analysis and opportunities for improvement. BMC Health Serv Res. 2014;14(122). doi:10.1186/1472-6963-14-122
Risk Management and Healthcare Policy

\section{Publish your work in this journal}

Risk Management and Healthcare Policy is an international, peerreviewed, open access journal focusing on all aspects of public health, policy, and preventative measures to promote good health and improve morbidity and mortality in the population. The journal welcomes submitted papers covering original research, basic science, clinical \& epidemiological studies, reviews and evaluations, guidelines, expert opinion and commentary, case reports and extended reports. The manuscript management system is completely online and includes a very quick and fair peer-review system, which is all easy to use. Visit http://www.dovepress.com/testimonials.php to read real quotes from published authors. 